\title{
Pemupukan Tanaman Karet (Hevea brasiliensis Muell Arg.) Menghasilkan di Kebun Sembawa, Sumatera Selatan
}

\section{Fertilization Plant Rubber ( $\underline{\text { Hevea }}$ brasiliensis Muell Arg.) Produce in Sembawa Estate, South Sumatra

\author{
Fitri Gumayanti dan Suwarto*
}

Departemen Agronomi dan Hortikultura, Fakultas Pertanian, Institut Pertanian Bogor (Bogor Agricultural University), Jl. Meranti, Kampus IPB Darmaga, Bogor 16680, Indonesia Telp.\&Faks. 62-251-8629353 e-mail agronipb@indo.net.id

*Penulis korespondensi : wrtskm@yahoo.com

Disetujui 4 Mei 2016/ Published online 9 Mei 2016

\begin{abstract}
The research activities aims to increase knowledge, skills, and experience on the rubber cultivation field, to study the fertilization and crop management and to analyze the relationship between rubber yield produced by fertilization which is done. Research activities conducted at the Research Estate of Sembawa Research, South Sumatra from February 2014 to June 2014. Fertilization is a rubber plant maintenance activities that important role in increasing the production of rubber. The precision fertilization conducted at the Estate Research of Sembawa Research that located in Sembawa generally has been following four exact criteria. Analysis of data fertilization with productivity data generated by simple regression and correlation at the 5\% level, which indicates that productivity is affected by the use of fertilizers and the two variables have a unidirectional relationship closeness.
\end{abstract}

Keywords: crop yield, precision fertilization, rubber

\begin{abstract}
ABSTRAK
Kegiatan penelitian ini bertujuan untuk meningkatkan pengetahuan, keterampilan, dan pengalaman lapangan tentang budi daya tanaman karet, mempelajari pengelolaan pemupukan tanaman karet menghasilkan, dan menganalisis hubungan produksi yang dihasilkan dengan pemupukan yang dilakukan. Kegiatan penelitian dilaksanakan di Kebun Riset Balai Penelitian Sembawa, Sumatera Selatan pada bulan Februari 2014 sampai Juni 2014. Pemupukan merupakan kegiatan pemeliharaan tanaman karet yang sangat berperan dalam peningkatan produksi karet. Ketepatan pemupukan yang dilakukan di Kebun Riset Balai Penelitian Sembawa lokasi Kebun Sembawa secara umum sudah mengikuti kriteria empat tepat. Analisis data pemupukan dengan data produktivitas yang dihasilkan dengan uji regresi sederhana dan korelasi pada taraf 5\% menunjukkan bahwa produktivitas dipengaruhi oleh dosis pupuk yang digunakan dan kedua peubah tersebut mempunyai hubungan keeratan searah.
\end{abstract}

Kata kunci : karet, ketepatan pemupukan, tanaman menghasilkan 


\section{PENDAHULUAN}

Karet merupakan salah satu komoditi pertanian yang sangat penting peranannya, baik sebagai sumber pendapatan, kesempatan kerja, dan sumber devisa negara. Indonesia merupakan negara dengan luas areal perkebunan karet terbesar di dunia yaitu 3.4 juta hektar diikuti Thailand seluas 2.6 juta hektar dan Malaysia 1.02 juta hektar. Hal tersebut berbeda dengan produksi karet Indonesia yang tercatat sebesar 2.7 juta ton berada dibawah produksi Thailand yang mencapai 3.1 juta ton, sedangkan produksi karet Malaysia mencapai 951 ribu ton (BPS 2012). Peningkatan produktivitas tanaman karet sangat perlu dilakukan, melihat prospek dan pengembangan agribisnis karet sangat bagus. Salah satu langkah yang perlu dilakukan dalam peningkatan produktivitas tanaman karet adalah dengan menerapkan praktik pertanian sesuai dengan rekomendasi dari balai penelitian tanaman karet, terutama pada kagiatan pemeliharaan tanaman khususnya pemupukan. Menurut Siregar dan Suhendry (2013) efektifitas dan efisiensi pemupukan sangat tergantung pada manajemen atau pengelolaannya di lapangan, yang nantinya akan sangat berperan dalam menetukan berbagai proses menuju realisasi produksi.

Pemupukan yang tidak tepat merupakan salah satu penyebab terlambatnya matang sadap dan rendahnya produktivitas tanaman karet. Selain itu, kekurangan atau kelebihan satu atau lebih unsur hara umumnya akan memperlihatkan gejala defisiensi. Menurut Soemarno (2013) gejala defisiensi unsur hara pada umumnya adalah munculnya gejala spesifik pada daun selama periode waktu yang berbeda-beda dalam masa pertumbuhan, abnormalitas internal, seperti tersumbatnya jaringan pembuluh, dan perbedaan hasil dengan atau tanapa gejala pada daun.

Menurut Samarappuli (2000) pengelolaan pemupukan di perkebunan karet menjadi sangat penting untuk diperhatikan dari segi ekonomi dan efisien pupuk yang dimanfaatkan. Penggunaan pupuk akan lebih efisien, jika status hara tanaman dikoreksi terlebih dahulu sebelum menentukan takaran pemupukan. Analisis hara tanaman dapat dilakukan secara teratur untuk menetapkan kebutuhan hara tanaman, serta memperhatikan ketepatan dosis/jumlah pupuk, waktu dan cara pemupukan (Boerhendhy dan Amypalupy, 2011).

Kegiatan penelitian ini dilaksanakan dengan tujuan untuk meningkatkan pengetahuan dan keterampilan tentang budi daya tanaman karet di lapangan, menganalisis produksi tanaman karet yang dihasilkan berdasarkan pemupukan yang dilakukan, dan mempelajari aspek pengelolaan pemupukan tanaman karet di Kebun Sembawa, Sumatera Selatan.

\section{BAHAN DAN METODE}

Kegiatan penelitian dilaksanakan di Kebun Sembawa, Sumatera Selatan. Pelaksanaan kegiatan berlangsung sejak bulan Februari 2014 sampai dengan bulan Juni 2014.

Kegiatan penelitian dilaksanakan dengan mengikuti kegiatan teknis dan kegiatan manajerial. Kegiatan teknis yang dilakukan meliputi kegiatan pemeliharaan, penyadapan, dan lain-lain dengan menjadi karyawan harian lepas (KHL). Kegiatan manajerial dilakukan dengan menjadi pendamping mandor kerja dan mandor besar/mandor wilayah serta pendamping asisten divisi. Masing-masing jabatan tersebut dilakukan setiap satu minggu selama satu bulan pada divisi yang berbeda, diawali dari Divisi Pembibitan, Divisi I, Divisi II, dan terakhir Divisi III. Kegiatan yang dilakukan mengikuti jadwal yang telah disiapkan oleh pihak Balai Penelitian sembawa sesuai dengan kegiatan yang ada di kebun. Masing-masing kegiatan penelitian yang telah dilakukan ditulis dalam jurnal harian kegiatan penelitian.

Pengamatan dilakukan dengan beberapa parameter untuk mendapatkan data primer, diantaranya adalah sebagai berikut; tepat dosis pupuk (diamati dengan mengambil 40 contoh tanaman pada beberapa tempat dari Blok yang dipupuk dan diulang tiga kali pada waktu yang berbeda), tepat tempat pupuk ditabur (mengambil 40 contoh tanaman dari Blok yang dipupuk di ulang tiga kali di waktu yang berbeda), gejala defisiensi hara (pengamatan dilakukan pada 300 tanaman contoh dipilih secara acak dalam baris. Gejala defisiensi hara diamati secara visual mengacu pada pustaka), tepat cara dan waktu, prestasi tenaga pemupuk, analisis hubungan antara pupuk dengan produksi.

Data diperoleh dari kantor kebun Balai Penelitian Sembawa berupa data pemupukan dan produksi tanaman karet selama lima tahun terakhir, kemudian di analisis secara deskriptif dan kuantitatif menggunakan uji statistika untuk melihat hubungan antara kedua peubah tersebut. Selain itu, data-data yang dikumpulkan adalah data tentang kebun seperti keadaan kebun, curah hujan, peta areal, keadaan tanaman dan produksinya, data pemupukan tanaman, data pola produktivitas tanaman tahun-tahun sebelumnya, struktur organisasi dan ketenagakerjaan, sarana dan prasarana kebun, serta studi berbagai pustaka. 
Data yang diperoleh dianalisis secara deskriptif dan kuantitatif. Analisis deskriptif dilakukan dengan menjelaskan hasil data berdasarkan perbandingan dengan data standar baku Kebun Riset Balai Penelitian Sembawa dan pustaka. Analisis kuantitatif dilakukan dengan menggunakan perhitungan matematis sederhana, serta persamaan regresi sederhana dan korelasi untuk menjelaskan hubungan antara data pemupukan dengan produktivitas tanaman karet dalam menghasilkan lateks.

\section{HASIL DAN PEMBAHASAN}

\section{Aspek Teknis}

Kegiatan teknis yang dilakukan meliputi semua kegiatan yang berkaitan dengan budi daya tanaman karet mulai dari persiapan bahan tanam hingga produksi. Penulis memperoleh pengetahuan dan keterampilan tentang teknik budi daya tanaman karet. Penulis berperan sebagai karyawan harian lepas dalam pelaksanaan kegiatan. Prestasi kerja yang diperoleh penulis selama mengikuti kegiatan teknis di lapangan ditunjukkan pada Tabel 1.

Berdasarkan tabel diatas menunjukkan bahwa prestasi kerja penulis pada beberapa kegiatan masih berada dibawah standar kerja kebun. Ketidaktercapaian standar tersebut disebabkan pengalaman dan keterampilan yang dimiliki penulis masih dibawah karyawan kebun. Hal tersebut disebabkan karyawan kebun mempunyai pengalaman kerja di lapangan yang lebih dan terbiasa dengan pekerjaan yang dilakukan sehingga dapat lebih terampil dan cepat dalam melakukan pekerjaan. Kendala yang ada saat di lapangan adalah kurangnya pengawasan dari mandor kerja, akibatnya pekerjaan selesai dengan standar kerja terpenuhi tetapi kualitas kerja kurang baik. Hal yang perlu dilakukan adalah memberikan pengawasan yang ketat dan memotivasi karyawan untuk bekerja dengan kuantitas kerja memenuhi standar dan didukung juga oleh kualitas kerja yang baik.

Tabel 1. Prestasi kerja yang dicapai penulis, karyawan, dan standar kerja

\begin{tabular}{|c|c|c|c|}
\hline Kegiatan & Standar kerja & Prestasi kerja karyawan & Prestasi kerja penulis \\
\hline \multicolumn{4}{|l|}{ Pembibitan } \\
\hline Pemanenan kecambah (batang $\mathrm{HK}^{-1}$ ) & 800 & 800 & 250 \\
\hline Penanaman kecambah (batang $\mathrm{HK}^{-1}$ ) & 800 & 800 & 250 \\
\hline Penanaman bibit entres (bibit $\mathrm{HK}^{-1}$ ) & - & 30 & 5 \\
\hline Okulasi pemurnian (okulasi $\mathrm{HK}^{-1}$ ) & - & 100 & 5 \\
\hline Penanaman bibit SMT (batang $\mathrm{HK}^{-1}$ ) & 1000 & 1000 & 1000 \\
\hline Pewiwilan bibit polybag (polybag $\mathrm{HK}^{-1}$ ) & 6000 & 6000 & 3000 \\
\hline Pembongkaran bibit SMT (batang HK $^{-1}$ ) & 1000 & 1000 & 500 \\
\hline Packing bibit SMT (batang $\mathrm{HK}^{-1}$ ) & 1500 & 1500 & 500 \\
\hline \multicolumn{4}{|l|}{ Pemeliharaan tanaman belum menghasilkan } \\
\hline Pengendalian gulma manual (ha $\mathrm{HK}^{-1}$ ) & 0.5 & 0.5 & 0.33 \\
\hline Pengendalian gulma kimiawi (tangki $\mathrm{HK}^{-1}$ ) & 12 & 12 & 3 \\
\hline Pembokoran (tanaman $\mathrm{HK}^{-1}$ ) & 80 & 80 & 10 \\
\hline Pewiwilan (ha $\mathrm{HK}^{-1}$ ) & 2 & $2-3$ & 2 \\
\hline Pengukuran lilit batang & - & 300 & 100 \\
\hline \multicolumn{4}{|l|}{ Pemeliharaan tanaman menghasilkan } \\
\hline Pengendalian gulma manual (ha $\mathrm{HK}^{-1}$ ) & 0.5 & 0.5 & 0.33 \\
\hline Pengendalian gulma imiawi (tangki $\mathrm{HK}^{-1}$ ) & 12 & 12 & 3 \\
\hline Pengendalian penyakit (pohon $\mathrm{HK}^{-1}$ ) & - & 30 & 5 \\
\hline
\end{tabular}

\section{Aspek Manajerial}

Manajemen Divisi Pembibitan dan Kebun Riset (Divisi I, Divisi II, dan Divisi III) Balai Penelitian Sembawa memiliki tugas dan tanggung jawab tertentu. Posisi tingkat manajemen yang diikuti oleh penulis selama kegiatan penelitian adalah pendamping asisten divisi, pendamping mandor wilayah, pendamping mandor kerja, krani divisi, dan krani timbang.

\section{Aspek Khusus}

Pemupukan. Pemupukan merupakan kegiatan memberikan sejumlah unsur hara yang dibutuhkan oleh tanaman. efetktivitas pemupukan berkaitan dengan tingkat hara pupuk yang dapat diserap tanaman, dan efisiensi pemupukan berkaitan dengan biaya yang dikeluarkan dengan tingkat produksi yang dihasilkan. Keberhasilan atau efektivitas pemupukan dipengaruhi oleh 
beberapa faktor seperti dosis pupuk, jenis pupuk, waktu dan frekuensi pemupukan, cara pemupukan, lokasi/tempat penaburan pupuk, dan pengendalian gulma, serta lama efektivitas suatu pupuk sangat mempengaruhi pertumbuhan dan perkembangan tanaman, dan dari aspek ekonomi lama efektivitas tersebut sangat berpengaruh terhadap biaya tambahan yang perlu dikeluarkan oleh pengusaha perkebunan (Wachjar dan Kadarisman 2007; Wijaya dan Hidayati 2012).

Ketepatan jenis. Pemilihan jenis pupuk yang digunakan juga perlu diperhatikan mengingat banyaknya jenis pupuk yang dijual di pasar dengan bentuk dan komposisi unsur. Pemupukan pada tanaman karet dapat menggunakan dua jenis pupuk, yaitu pupuk tunggal dan pupuk majemuk khusus tanaman karet. Menurut Sutarta et al. (2003) penggantian satu jenis pupuk dengan jenis pupuk lainnya dapat dilakukan dengan memperhatikan kandungan unsur hara serta keseimbangan dan pengaruh bahan ikutannya.

Jenis pupuk untuk TM karet di Kebun Riset

Balai Penelitian Sembawa lokasi Kebun Sembawa menggunakan jenis pupuk majemuk slow realese khusus tanaman karet, terdiri dari $18 \%$ unsur $\mathrm{N}, 6 \%$ unsur $\mathrm{P}, 16 \%$ unsur $\mathrm{K}, 4 \%$ unsur $\mathrm{CaO}, 2 \%$ unsur $\mathrm{MgO}$, dan $1 \%$ unsur $\mathrm{TE}$ $(\mathrm{Cu}+\mathrm{Zn})$. Menurut Poeloengan et al. (2003) pupuk majemuk mempunyai keunggulan dibandingkan dengan pupuk tunggal, yaitu lebih praktis dalam pemesanan, transportasi, penyimpanan, dan aplikasi di lapangan karena satu jenis pupuk majemuk mengandung seluruh atau sebagian besar hara yang dibutuhkan tanaman.

Jenis pupuk yang diaplikasikan pada TM karet yang diamati adalah jenis pupuk tunggal. Hal tersebut dilakukan karena alasan kondisi tanaman dan hasil analisis daun oleh peneliti yang menyatakan Blok I tahun tanam 2008 mengalami kekurangan salah satu unsur hara.

Ketepatan dosis. Penulis mengamati ketepatan dosis pada satu blok (Blok I tahun tanam 2008) dengan tiga kali pengamatan dengan waktu yang berbeda. Jenis pupuk yang diaplikasikan adalah pupuk tunggal (Urea, TSP, dan $\mathrm{KCl})$. Ketepatan dosis pupuk yang diaplikasikan ditunjukkan pada Tabel 2.

Tabel 2. Ketepatan dosis aplikasi pemupukan di lapangan

\begin{tabular}{cccccc}
\hline Ulangan & $\begin{array}{c}\text { Jumlah Tanaman } \\
\text { Contoh }\end{array}$ & $\begin{array}{c}\text { Dosis pupuk }(\mathrm{g}) \\
\text { pohon }^{-1}\end{array}$ & $\begin{array}{c}\sum \text { Tanaman tidak } \\
\text { tepat dosis }\end{array}$ & $\begin{array}{c}\text { Persentase } \\
\text { ketidaktepatan }(\%)\end{array}$ & $\begin{array}{c}\text { Persentase } \\
\text { ketepatan }(\%)\end{array}$ \\
\hline 1 & 40 & 500 & 7 & 17.5 & 82.5 \\
2 & 40 & 500 & 9 & 22.5 & 77.5 \\
3 & 40 & 500 & 6 & 15.0 & 85.0 \\
\hline Rata-rata & & & 7.33 & & 81.7 \\
\hline Sumber:
\end{tabular}

Sumber : Data primer (2014)

Persentase ketepatan dosis yang dicapai saat pelaksanaan pemupukan adalah sebesar 81.7 $\%$ (Tabel 3) pencapaian tersebut belum memenuhi standar ketepatan dosis. Standar persentase ketepatan dosis pupuk di Kebun Riset Balai Penelitian Sembawa lokasi Kebun Sembawa sebesar 90-100\%. Hal tersebut dikarenakan terdapat beberapa orang penabur pupuk yang kurang memperhatikan dosis pupuk yang seharusnya diaplikasikan pada tanaman, terutama pada bagian tengah dan akhir lokasi penebaran pupuk. Langkah yang harus dilakukan untuk mengatasi hal tersebut adalah dengan menambah tingkat pengawasan pada tenaga pemupuk terutama di tengah dan akhir lokasi pemupukan, dan memotivasi karyawan untuk lebih memperhatikan kualitas kerja dengan tetap mempertahankan atau meningkatkan kuantitas kerja. Tanaman yang dipupuk tidak sesuai dengan dosisnya akan mengakibatkan defisiensi hara dan mempengaruhi produksi dua tahun berikutnya. Jumlah tanaman tidak tepat dosis ditentukan berdasarkan penimbangan pupuk yang akan diaplikasikan penabur pada lubang pupuk. Jika dosis pupuk yang diaplikasikan kurang atau lebih dari $500 \mathrm{~g}_{\text {pohon }}{ }^{-1}$ maka dinyatakan tidak tepat.

Ketepatan lokasi/tempat tabur pupuk. Penyerapan hara yang efektif berkaitan dengan tempat/lokasi pupuk yang ditabur dan letak perakaran tanaman, yaitu bagaimana pupuk tersebut cepat sampai ke zona perakaran dan seminimum mungkin terjadi kehilangan pupuk akibat penguapan dan aliran permukaan. Aplikasi pemupukan yang dilakukan di Kebun Riset Balai Penelitian Sembawa lokasi Kebun Sembawa diletakkan di atas permukaan tanah dengan standar jarak lubang tabur pupuk dari pohon 50-150 cm. Tabel 3 menunjukkan ketepatan tempat aplikasi pemupukan. 
Berdasarkan Tabel 3 bahwa persentase ratarata ketepatan tempat penaburan pupuk dengan mengukur jarak lubang pupuk dari tanaman sebesar $85 \%$, dan rata-rata lubang tabur pupuk yang tidak tepat dengan standar adalah 6 pohon dari 40 pohon yang diamati atau sekitar $15 \%$. Hal ini menunjukkan bahwa pemupukan yang dilakukan telah memenuhi konsep tepat lokasi/tempat tabur pupuk dengan standar persentase ketepatan adalah 80-100\%. Ketercapaian tersebut harus dipertahankan bahkan ditingkatkan karena berdasarkan pengamatan penulis masih terdapat karyawan yang lebih mengutamakan kuantitas pekerjaan dibandingkan kualitas kerjanya. Oleh karena itu, dalam kegiatan pembuatan lubang pupuk baik asisten maupun mandor harus tetap melakukan pengawasan yang lebih terhadap kerja karyawan.

Tempat/lokasi penaburan pupuk pada tanaman karet menghasilkan hendaknya ditebar merata secara larikan dengan jarak 150-200 cm dari pohon (Siregar dan Suhendry, 2013). Berdasarkan standar yang ditetapkan dan pustaka tersebut, maka penentuan jumlah tanaman yang tidak tepat tempat/lokasi penaburan pupuk adalah jarak tabur pupuk yang kurang dari $50 \mathrm{~cm}$ dari pohon.

Tabel 3. Ketepatan lokasi/tempat penaburan pupuk (jarak lubang pupuk dari pohon)

\begin{tabular}{cccccc}
\hline Ulangan & $\begin{array}{c}\text { Jumlah } \\
\text { Tanaman } \\
\text { Contoh }\end{array}$ & $\begin{array}{c}\text { Standar lokasi penaburan pupuk } \\
(\mathrm{cm})\end{array}$ & $\begin{array}{c}\text { 急 Tanaman } \\
\text { tidak tepat }\end{array}$ & $\begin{array}{c}\text { Persentase } \\
\text { ketidaktepatan } \\
(\%)\end{array}$ & $\begin{array}{c}\text { Persentase } \\
\text { ketepatan } \\
(\%)\end{array}$ \\
\hline 1 & 40 & $50-100$ & 8 & 20.0 & 80.0 \\
2 & 40 & $50-100$ & 7 & 17.5 & 82.5 \\
3 & 40 & $50-100$ & 3 & 7.5 & 92.5 \\
\hline Rata-rata & & & 6 & 85.0
\end{tabular}

Sumber : Data primer (2014)

Ketepatan cara dan waktu. Umumnya cara pemupukan yang dilakukan pada perkebunan ada dua, yaitu secara manual dan mekanis. Aplikasi pemupukan dengan cara manual ada dua cara yang umum dilakukan, yaitu cara tebar langsung dan cara dibenamkan dalam lubang pupuk (pocket) (Chandra, 2012). Pemupukan yang dilakukan di Kebun Riset Balai Penelitian Sembawa lokasi Kebun Sembawa yaitu secara manual dengan di benamkan dalam lubang pupuk sebanyak dua lubang pupuk setiap tanaman. Cara ini diharapkan pupuk yang diaplikasikan tidak hilang akibat aliran permukaan.
Pengamatan yang dilakukan penulis didasarkan pada cara penaburan pupuk ke dalam lubang pupuk, ditutup atau tidaknya lubang pupuk setelah pupuk dimasukkan, dan pupuk yang diaplikasikan tercampur merata dan tidak ada bongkahan. Hasil yang diperoleh penulis dari 10 tenaga pemupuk yang diamati bahwa rata-rata cara yang dilakukan adalah tepat (Tabel 4), meskipun masih terdapat beberapa lubang pupuk tanaman yang tidak tertutup, masih terdapat bongkahan pada pupuk yang ditabur, dan aplikasi pupuk yang belum merata tercampur dari tiga jenis pupuk yang digunakan.

Tabel 4. Ketepatan pemupukan tenaga pemupuk

\begin{tabular}{ccccc}
\hline Pemupuk & Tepat dosis & Tepat tempat & Tepat cara & Tepat waktu \\
\hline 1 & 1 & 2 & 3 & 3 \\
2 & 2 & 2 & 2 & 3 \\
3 & 2 & 2 & 2 & 3 \\
4 & 2 & 2 & 3 & 3 \\
5 & 2 & 3 & 2 & 3 \\
6 & 2 & 2 & 3 & 3 \\
7 & 1 & 2 & 3 & 3 \\
8 & 2 & 2 & 3 & 3 \\
9 & 2 & 3 & 3 & 3 \\
\hline
\end{tabular}

${ }^{\mathrm{a}} 1$ (kurang tepat), 2 (tepat), 3 (sangat tepat) Sumber : Data primer (2014)

Waktu pemupukan yang tepat adalah saat tanah masih dalam keadaan lembab, penetapan waktu pemupukan didasarkan pada pola curah hujan, dan pelaksanaan pemupukan tepat waktu 
sulit dilakukan karena kondisi curah hujan yang sulit diprediksi. Hal ini akan berakibat pada kurangnya efektivitas pemupukan. (Setyamidjaja, 1993; Winarna et al., 2003; Adiwiganda, 2007). Waktu realisasi pemupukan yang dilakukan pada TM tahun tanam 2008 tidak sesuai dengan rencana pemupukan yang telah dibuat. Aplikasi pemupukan tanaman karet menghasilkan di Kebun Sembawa sebenarnya diaplikasikan sebanyak satu tahun sekali pada bulan Oktober/ November (awal musim hujan) menggunakan pupuk majemuk slow release khusus tanaman karet. Berdasarkan hasil rekomendasi dari peneliti bagian tanah dan pemupukan Balai Penelitian Sembawa yang menyatakan bahwa tanaman karet tahun tanam 2008 mengalami gejala defisiensi salah satu unsur hara makro, maka dilakukan pemupukan dengan pupuk tunggal sehingga untuk tahun 2014 tanaman menghasilkan tersebut dipupuk sebanyak dua kali dalam setahun (April dan Oktober).

Prestasi kerja. Standar kerja untuk pemupukan adalah 1 ha $\mathrm{HK}^{-1}$ penabur pupuk.
Prestasi kerja yang diperoleh tenaga pemupuk selama dua kali pemupukan telah memenuhi standar kerja pemupukan, dengan masing-masing prestasi kerja per hari secara berurutan sebesar 1 ha $\mathrm{HK}^{-1}$ dan 1.16 ha $\mathrm{HK}^{-1}$.

Ketercapaian prestasi kerja karyawan tidak hanya kuantitas tetapi didukung juga oleh empat tepat pemupukan yang dari keempat tersebut ratarata telah tepat dilaksanakan, kecuali pada tingkat ketepatan dosis yang masih sangat rendah (Tabel 4). Prestasi kerja kegiatan pemupukan di Kebun Riset Balai Penelitian Sembawa lokasi Kebun Sembawa ditunjukkan pada Tabel 5. Hal ini sangat perlu diperhatikan dan dapat menjadi dasar untuk menambah jumlah mandor yang mengawasi kegiatan pemupukan agar tidak terjadi penaburan pupuk yang tidak sesuai dengan dosis yang ditentukan. Menurut Pahan (2010) prestasi kerja tenaga penabur pupuk dipengaruhi oleh dosis pupuk per tanaman, topografi areal, dan keterampilan tenaga penabur.

Tabel 5. Prestasi tenaga kerja pemupuk

\begin{tabular}{clcccccc}
\hline Tanggal & \multicolumn{2}{c}{ Jenis pupuk } & $\begin{array}{c}\text { Dosis aplikasi } \\
(\mathrm{g}) \text { tanaman }^{-1}\end{array}$ & Luas (ha) & $\begin{array}{c}\text { Standar kerja } \\
\text { (ha HK } \mathrm{HK}^{-1}\end{array}$ & $\begin{array}{c}\text { N Tenaga } \\
\text { pemupuk (orang) }\end{array}$ & $\begin{array}{c}\text { Prestasi kerja } \\
\text { (ha HK }\end{array}$ \\
\hline $02 / 04 / 2014$ & $\begin{array}{l}\text { Tunggal } \\
\text { TSP, KCl) }\end{array}$ & (Urea, & 500 & 18.00 & 1 & 18 & 1.00 \\
03/04/2014 & $\begin{array}{l}\text { Tunggal } \\
\text { TSP, KCl) }\end{array}$ & (Urea, & 500 & 20.92 & 1 & 18 & 1.16 \\
\hline
\end{tabular}

Sumber : Data primer (2014)

Defisiensi unsur hara. Defisiensi hara pada tanaman terjadi akibat rendahnya ketersediaan hara dalam tanah. Rendahnya ketersediaan hara tersebut dapat diatasi salah satunya dengan pemupukan. Ketersediaan unsur hara makro sangat dibutuhkan tanaman dalam jumlah banyak untuk mendukung produksi seperti N, P, K, dan $\mathrm{Mg}$. Faktor-faktor yang menyebabkan timbulnya gejala defisiensi hara pada tanaman karet adalah faktor teknis dan faktor manajerial dalam pelaksanaan pemupukan yang kurang tepat. Penulis melakukan pengamatan gejala visual terhadap gejala defisiensi unsur hara N, P, K, dan $\mathrm{Mg}$ pada daun tanaman karet menghasilkan. Hasil pengamatan menunjukkan bahwa persentase defisiensi masing-masing unsur hara secara berurutan sebesar $0.08 \%, 1 \%, 0.5 \%$, dan $0.58 \%$ (Tabel 6).

Tabel 6. Gejala visual defisiensi unsur hara pada tanaman karet

\begin{tabular}{cccccccc}
\hline \multirow{2}{*}{ Tahun tanam } & $\begin{array}{c}\text { Tanaman } \\
\text { diamati }\end{array}$ & $\begin{array}{c}\text { Tanaman } \\
\text { Sehat }\end{array}$ & $\begin{array}{c}\text { T Tanaman } \\
\text { sakit }\end{array}$ & \multicolumn{4}{c}{$\sum$ Tanaman defisiensi Hara } \\
\cline { 6 - 8 } & 300 & 237 & 63 & 0 & 4 & 5 & 3 \\
2001 & 300 & 245 & 55 & 0 & 0 & 0 & 1 \\
2006 & 300 & 210 & 90 & 0 & 2 & 0 & 3 \\
2008 & 300 & 185 & 115 & 1 & 6 & 1 & 0 \\
\hline Jumlah & 1200 & 877 & 323 & 1 & 12 & 6 & 7 \\
\hline Persentase $(\%)$ & & 73.08 & 26.92 & 0.08 & 1 & 0.5 & 0.58 \\
\hline
\end{tabular}

Sumber : Data primer (2014)

Persentase defisiensi unsur hara yang terjadi pada tanaman karet menghasilkan jika dihubungkan dengan kandungan hara tanaman karet hasil analisis LSU (Leaf Sampling Unit), 
terlihat bahwa status hara tanaman karet rata-rata berlebih (Tabel 7). Hal ini berarti tanaman karet yang mengalami gejala defisiensi atau kekurangan hara rendah.

Tabel 7. Kandungan hara daun tanaman karet

\begin{tabular}{cccccccccc}
\hline \multirow{2}{*}{$\begin{array}{c}\text { Tahun } \\
\text { tanam }\end{array}$} & \multirow{2}{*}{ LSU } & \multicolumn{7}{c}{ Kandungan hara daun (\%) } \\
\cline { 2 - 10 } & & $\mathrm{N}$ & Status hara & $\mathrm{P}$ & Status hara & $\mathrm{K}$ & Status hara & $\mathrm{Mg}$ & Status hara \\
\hline 1995 & $206 \mathrm{~B}$ & 2.82 & - & 0.38 & + & 1.95 & + & 0.35 & + \\
2001 & $107 \mathrm{~A}$ & 2.98 & - & 0.40 & + & 2.25 & + & 0.35 & + \\
2006 & 112 & 3.60 & + & 0.44 & + & 1.49 & + & 0.39 & + \\
2008 & 113 & 3.18 & - & 0.43 & + & 1.41 & + & 0.39 & + \\
\hline
\end{tabular}

${ }^{\mathrm{a}}$ kelebihan (+), kekurangan (-), LSU (Leaf Sampling Unit)

Sumber : Rekomendasi pemupukan untuk tahun 2013-2014

\section{Produktivitas}

Pemupukan merupakan salah satu faktor yang mempengaruhi produktivitas. Faktor-faktor lainnya antara lain adalah kesehatan tanaman, curah hujan, pertumbuhan gulma di daerah sekitar tanaman, dan keadaan iklim. Menurut Nugroho dan Istianto (2009) pemupukan yang teratur pada TM karet dapat meningkatkan produktivitas sebesar $15-25 \%$.

Perbandingan antara pemupukan yang dilakukan dengan produktivitas yang diperoleh di Kebun Riset Balai Penelitian Sembawa lokasi Kebun Sembawa selama sembilan tahun terakhir (Tabel 8) terlihat bahwa perubahan dosis pupuk yang diaplikasikan setiap tahun diikuti oleh peningkatan produktivitas per tahunnya. Selain itu, penurunan produktivitas terjadi pada tahun 2012 dengan pengurangan dosis pupuk yang diaplikasikan dari tahun sebelumnya. Respon produktivitas $(\mathrm{Y})$ terhadap dosis pupuk $(\mathrm{X})$ adalah nyata $(\mathrm{p}$-value $=0.025)$, dengan persamaan regresi $\mathrm{Y}=1198+0.928 \mathrm{X}$, artinya bahwa dengan penambahan dosis pupuk sebesar $1 \mathrm{~kg} \mathrm{ha}^{-1}$ akan meningkatkan produktivitas karet sebesar $0.928 \mathrm{~kg}$ karet kering ha ${ }^{-1}$. Kedua peubah tersebut mempunyai hubungan keeratan yang searah dengan nilai korelasi (r) sebesar 0.77. Hasil tersebut diperoleh dari pengujian regresi sederhana dan korelasi pada data pemupukan yang dilakukan dengan data produktivitas yang dihasilkan pada taraf 5\%.

Tabel 8. Data dosis pemupukan dan produktivitas

\begin{tabular}{cccc}
\hline Tahun & Luas TM (ha) & Dosis $\left(\mathrm{kg} \mathrm{ha}^{-1}\right)$ & Produktivitas $\left(\mathrm{kg} \mathrm{karet} \mathrm{kering} \mathrm{ha}^{-1}\right)$ \\
\hline 2005 & 1084.02 & 37.12 & 1174.33 \\
2006 & 1085.32 & 148.61 & 1190.80 \\
2007 & 1116.68 & 109.53 & 1201.32 \\
2008 & 1125.71 & 153.06 & 1321.65 \\
2009 & 1133.16 & 93.91 & 1321.86 \\
2010 & 1156.34 & 188.03 & 1330.98 \\
2011 & 996.45 & 314.92 & 1604.53 \\
2012 & 938.57 & 185.84 & 1590.53 \\
2013 & 923.60 & 567.17 & 1659.43 \\
\hline
\end{tabular}

Sumber : Laporan manajemen kebun 2005-2013

\section{KESIMPULAN}

Kegiatan penelitian dapat meningkatkan pengetahuan dan keterampilan mengenai budi daya tanaman karet secara keseluruhan, melalui kegiatan teknis dan manajerial. Pengelolaan pemupukan di Kebun Riset Balai Penelitian Sembawa lokasi Kebun Sembawa secara umum telah sesuai dengan standar yang ditetapkan, mulai dari perencanaan hingga aplikasi teknis di lapangan. Ketepatan pemupukan yang masih belum sesuai dengan standar atau rekomendasi dari kebun adalah ketepatan dosis. Analisis data pemupukan dengan data produktivitas yang dihasilkan dengan uji regresi sederhana dan korelasi pada taraf 5\% menunjukkan bahwa produktivitas dipengaruhi oleh dosis pupuk yang digunakan dan kedua peubah tersebut mempunyai hubungan keeratan searah.

\section{DAFTAR PUSTAKA}

[BPS] Badan Pusat Statistik. 2012. Data produksi dan luas areal tanaman karet [internet]. [diunduh pada 2013 November 25]. Tersedia pada: http://bps.go.id/tab_sub/ view.php?kat $=3 \&$ 
Boerhendhy, I., Amypalupy, K. 2011. Optimalisasi produktivitas karet melalui penggunaan bahan tanam, pemeliharaan, sistem eksploitasi, dan peremajaan tanaman. Litbang pertanian. 30(1): 23-30.

Chandra, W. 2012. Studi pemupukan kelapa sawit (Elais guineensis Jacq.) tanaman menghasilkan (TM) di perkebunan Bangun Koling Estate, PT. Windu Nabatindo Abadi, Bumitama Gunajaya Agro Grup, KotawaringinTimur, Kalimantan Tengah. Skrpsi. Institut Pertanian Bogor, Bogor.

Nunggroho, P.A., Istianto. 2009. Pentingnya Pemupukan Tanaman Karet. LPPcom Balai Penelitian Sungai Putih. hlm 18.

Pahan, I. 2010. Panduan Lengkap Kelapa Sawit Manajemen Agribisnis dari Hulu hingga Hilir. Penebar Swadaya, Jakarta.

Poelongan, Z., Fadli, M. L., Winarna, Rahutomo, S., Sutarta, E, S. 2003. Permasalahan Pemupukan pada Perkebunan kelapa Sawit.W. Darmosarkoro, E. S. Sutarta, Winarna, editor. Lahan dan Pemupukan Sawit. Pusat Penelitian Kelapa Sawit, Medan.

Samarappuli, L. 2000. Ekonomi dan efisiensi pupuk di pemanfaatan karet belum menghasilkan. Bul. Research Rubber Institute Sri Lanka. 42:1-10.

Setyamidjaja, D. 1993. Seri Budidaya Karet. Kanisius, Yogyakarta. hlm 51.
Siregar, Tumpal, H, S., Suhendry, I. 2013. Budidaya dan Teknologi Karet. Penebar Swadaya, Jakarta. hlm 105-107.

Soemarno. 2013. Model Evaluasi Kesuburan Tanah dan Rekomendasi Pemupukan. Jurusan Tanah FPUB, Malang. hlm 1-3.

Sutarta, E.S., Rahutomo, W., Darmokarkoro, Winarna. 2003. Peranan Unsur Hara dan Sumber Hara pada Pemupukan Kelapa Sawit. W. Darmosarkoro, E. S. Sutarta, Winarna, editor. Lahan dan Pemupukan Sawit. Pusat Penelitian Kelapa Sawit, Medan.

Wachjar, A., Kadarisman, L. 2007. Pengaruh kombinasi pupuk organik cair dan pupuk anorganik serta frekuensi aplikasi terhadap pertumbuhan tanaman kakao (Thoubroma cacao) belum menghasilkan. Bul, Agron. 35(3): 212-216.

Wijaya, T., Hidayati, U. 2012. Saptabina Usahatani Karet Rakyat : Pemupukan. Balai Penelitian Sembawa-Pusat Penelitian Karet, Palembang. hlm 60.

Winarna, W., Darmosarkoro, Sutarta, E, S. 2003. Teknologi Pemupukan Tanaman Kelapa Sawit. W Darmosarkoro, ES Sutarta, Winarna, editor. Lahan dan Pemupukan Kelapa Sawit. Pusat Penelitian Kelapa Sawit, Medan. 